\title{
El Reglamento Interno de Trabajo como fuente de Derecho: importancia y visión jurisprudencial ${ }^{(* *)}$
}

\section{The Internal Labor Regulations as a source of Law: importance and jurisprudential vision}

\begin{abstract}
Resumen: El Reglamento Interno de Trabajo es una norma que puede ser creada por el empleador. En ese sentido, su posición en el sistema de fuentes es residual dado que no puede contravenir el contenido de las normas heterónomas, ni tampoco al convenio colectivo. Sin embargo, la jurisprudencia lo ha considerado muchas veces para evaluar la validéz de un despido o la existencia de una relación laboral. El presente artículo busca repasar esos temas, así como evaluar la vigencia de la norma que lo regula (Decreto Supremo 39-91-TR).
\end{abstract}

Palabras Clave: Reglamento Interno de Trabajo - Despido - Poder de Dirección - Contrato de Trabajo

\begin{abstract}
The Internal Labor Regulations is a rule law that could be created by the employer. In that sense, its position in the system of sources is residual because it can not contravene the government rules nor the collective agreement content. However, case law has considered it many times to assess the validity of a dismissal or the existence of an employment relationship. This article seeks to review these issues and to assess the validity of the rule that regulates it (Supreme Decree 39-91-TR).
\end{abstract}

Keywords: Internal Labor Regulations - Dismissal - Employer's Power Labor Contract

Resulta curioso que el derecho del trabajo le reconozca poder jurídico a quien normalmente ya cuenta con poder (el económico). Pero desde siempre fue así, nuestra disciplina reconoce el poder de dirección al empleador lo cual le permite dirigir, fiscalizar y sancionar al trabajador,

(*) Abogado por la Pontificia Universidad Católica del Perú. Máster Interuniversitario en Empleo, Relaciones Laborales y Diálogo Social en Europa. Doctor en Derecho por la Universidad de Castilla La Mancha. Estudios de postgrado en la Universidad de Buenos Aires, en el Centro Internacional de Formación de la OIT en Turín, en la Universidad de Boloña y en la Universidad de Castilla La Mancha. Profesor Ordinario de Derecho del Trabajo en la Facultad de Derecho de la Pontificia Universidad Católica del Perú, Director de la Maestría de Relaciones Laborales en la misma casa de estudios. Docente en la Universidad ESAN. Experto en Derecho Laboral. Correo electrónico: dulloa@pucp.edu.pe

$\left.{ }^{(* *}\right)$ Nota del Editor: El artículo fue recibido el 31 de octubre de 2016 y aprobada su publicación el 25 de noviembre del mismo año. 


\author{
El Reglamento Interno de Trabajo como fuente de Derecho: importancia y \\ visión jurisprudencial \\ The internal labor regulations as a source of Law: importance and \\ jurisprudential vision
}

dada la subordinación por la cual este último se obliga a prestar sus servicios, siendo una de las manifestaciones de dicho poder el reglamento interno de trabajo, esto es, la herramienta que le permite al empleador consolidar de manera expresa las diferentes instrucciones que se aplicarán en su ámbito, pues él "determina las condiciones a que deben sujetarse los empleadores y trabajadores en el cumplimiento de sus prestaciones"(1).

El reglamento interno de trabajo cumple así varias funciones:

- Es una manifestación del poder de dirección (Boza 2011, 128-133).

- A pesar de ser una manifestación unilateral de un sujeto privado(2), es una norma jurídica (aunque del último nivel jerárquico) y, por tanto, prevalece sobre lo establecido en los contratos de trabajo (Neves 2009, 98).

- Su incumplimiento configura una falta grave que puede justificar el despido según lo previsto en el literal a del artículo 25 de la ley de productividad y competitividad laboral.

- Sujetarse a él supone una evidencia de laboralidad.

En el Perú, la única norma que regula este documento es el Decreto Supremo 39-91-TR, publicado el 31 de diciembre de 1991, el mismo que establece:

- Un contenido normativo del reglamento interno. Luego veremos si esto es un conjunto mínimo o solamente referencial.

- La obligación de contar con uno en las empresas con más de cien trabajadores, esto es, con ciento uno(3).

- La obligación de presentarlo a la autoridad de trabajo para su aprobación automática.
- La obligación de entregar un ejemplar del reglamento a los trabajadores dentro de los cinco días naturales de presentado a la autoridad.

- La posibilidad de impugnarlo por parte de los trabajadores siempre que alguna norma viole una disposición legal o convencional.

Respecto a los temas incluidos en el contenido del reglamento interno, el artículo 2 de la norma citada señala lo siguiente:

"El reglamento interno de trabajo deberá contener las principales disposiciones que regulan las relaciones laborales, entre ellas:

a) Admisión o ingreso de los trabajadores;

b) Las jornadas y horarios de trabajo; tiempo de la alimentación principal;

c) Normas de control de asistencia al trabajo;

d) Normas de permanencia en el puesto conteniendo: permisos, licencias e inasistencias;

e) Modalidad de los descansos semanales;

f) Derechos y obligaciones del empleador;

g) Derechos y obligaciones del trabajador;

h) Normas tendientes al fomento y mantenimiento de la armonía entre trabajadores y empleadores;

(1) Artículo 1 del Decreto Supremo 39-91-TR.

(2) Ello no es así en otros países. Por ejemplo, en México, el Reglamento Interior de Trabajo se formula por una comisión mixta de representantes de los trabajadores y del patrón, tal como lo señala el artículo 424 de la ley federal del trabajo.

(3) Lo referente al número mínimo es algo discrecional y poco lógico en un país donde la mayoría de trabajadores laboran en empresas con poco personal. Por ejemplo, en Colombia es obligatorio para todo empleador que ocupe más de cinco trabajadores de carácter permanente en empresas comerciales, más de diez en empresas industriales o más de veinte en empresas agrícolas, ganaderas o forestales. 


\section{Daniel Ulloa Millares}

i) Medidas disciplinarias;

j) Persona o dependencia encargada de atender los asuntos laborales y la tramitación de los mismos;

k) Normas elementales que se deben observar dentro del desarrollo de la actividad laboral, con la finalidad de cautelar la higiene y seguridad en el trabajo, e indicaciones para evitar accidentes u otros riesgos profesionales, así como las instrucciones respectivas para prestar los primeros auxilios;

I) Las demás disposiciones que se consideren convenientes de acuerdo a la actividad de la empresa".

De hecho, este contenido ha venido siendo entendido por la autoridad de trabajo como un contenido mínimo obligatorio, ya que muchas veces ha observado el texto de algunos reglamentos internos presentados para su aprobación por no contar con artículos que comprendan estos títulos.

Lo anterior parecería absurdo considerando las numerosas normas laborales vigentes emitidas con posterioridad al Decreto Supremo 39-91-TR que regulan los temas citados, por ejemplo, la ley de productividad y competitividad laboral(4), las normas sobre tiempo de trabajo y el registro de control

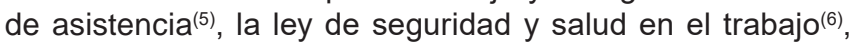
etcétera, todas ellas que a su vez restringen la autonomía del empleador para la regulación de esos temas.

Asimismo, parecería contradictorio que el trabajador sepa cuáles son los criterios para la admisión o ingreso al trabajo dado que ya superó esa etapa. En todo caso, un tema más importante supondría la regulación, por ejemplo, de las condiciones para el ascenso o promoción en su trabajo, esto es, aquellos temas que todavía no tienen regulación en las normas heterónomas.

Cabe señalar que otras normas han impuesto temas de inclusión obligatoria en el reglamento interno, a saber:

- $\quad$ Normas sobre VIH y sida (artículo 2 de la Resolución Ministerial No. 376-2008-TR) ${ }^{(7)}$,

- Normas sobre la prohibición de fumar (último párrafo del numeral 12.1 del reglamento de la Ley 28705 , ley general para la prevención y control de los riesgos del consumo del tabaco, aprobado por Decreto Supremo 15-2008-SA y modificado por Decreto Supremo 1-2011$\mathrm{SA})^{(8)}$,

- Normas sobre protección a trabajadores con tuberculosis (numeral 7.3. del reglamento de la Ley 30287 , ley de prevención y control de la tuberculosis en el Perú, aprobado por Decreto Supremo 21-2015-SA) ${ }^{(9)}$.

En palabras simples, en muchos aspectos el reglamento interno de trabajo se convierte actualmente en una compilación o síntesis de la legislación laboral, cuando en nuestra

(4) Aprobada por Decreto Supremo 3-97-TR.

(5) Decreto Supremo 7-2002-TR, Decreto Supremo 8-2002-TR, Decreto Supremo 4-2006-TR y Decreto Supremo 11-2006-TR.

(6) Ley 29783

(7) Artículo 2.- Dar un plazo de noventa (90) días hábiles a los empleadores para adaptar sus reglamentos internos de trabajo y su organización laboral, al cumplimiento de las medidas frente al VIH y SIDA en el lugar de trabajo.

(8) Sin perjuicio de lo expuesto, los Reglamentos Internos de Trabajo de las entidades públicas o empresas privadas deben incluir la prohibición expresa de fumar en todas sus instalaciones, así como los mecanismos internos para denunciar a quienes fumen donde esté prohibido.

(9) "7.3 Los empleadores del sector público y privado deberán implementar medidas en sus reglamentos internos de trabajo y su organización laboral orientadas a prevenir y sancionar la comisión de actos discriminatorios hacia una persona afectada por tuberculosis". 


\author{
El Reglamento Interno de Trabajo como fuente de Derecho: importancia y \\ visión jurisprudencial \\ The internal labor regulations as a source of Law: importance and \\ jurisprudential vision
}

opinión su objetivo debería ser otro, cual es complementar lo ya existente o regular los temas no previstos en las normas.

Por otro lado, la obligación de presentar el Reglamento Interno de Trabajo a la autoridad, además de tener que entregarlo a cada trabajador en un plazo corto, desincentiva la flexibilidad de este documento, por lo que es común encontrar que los empleadores opten por establecer por separado o mediante políticas o directivas específicas la regulación de determinados temas (por ejemplo, manejo de redes o correos electrónicos; uniformes de trabajo; etcétera).

El contenido del Reglamento Interno de Trabajo es un tema aparte, pues ello posee relevancia como ejercicio de la facultad disciplinaria. Así, la jurisprudencia de nuestro Tribunal Constitucional (en adelante, "TC") la ha vinculado con el principio de tipicidad y ha exigido la observancia de los parámetros disciplinarios incluidos en el reglamento interno para avalar un cese. Esto es, la aplicación de los principios de debido proceso así como los de racionabilidad y proporcionalidad.

En efecto, dado que los jueces siempre evalúan la forma en que el empleador califica las faltas, especialmente cuando la sanción es el despido, la sentencia de fecha 18 de agosto de 2004 que resuelve el expediente No. 1058-2004 (caso Serpost) realizó un análisis del reglamento interno del empleador y su aplicación como sustento del cese.

En este caso, el trabajador acusó:

"Que la demandada le ha atribuido arbitrariamente la comisión de una supuesta falta grave contemplada en el inciso a del artículo 25 del Texto Único Ordenado del Decreto Legislativo 728, aprobado por Decreto Supremo 003-97-TR, argumentando "[...] haber utilizado indebidamente los recursos públicos dentro del horario de trabajo para realizar actividades de índole particular, totalmente ajenas al servicio, constatándose el envío de material pornográfico a través del sistema de comunicación electrónico, denotando falta de capacidad e idoneidad para el desempeño del cargo e inobservancia del Reglamento Interno de Trabajo' (énfasis agregado).

Y el TC señaló lo siguiente:
"5) En primer lugar y si la supuesta falta grave atribuida al recurrente se sustenta en el hecho de "haber utilizado indebidamente recursos públicos dentro del horario [d]e trabajo, para realizar labores de índole particular, totalmente ajenas al servicio, constatándose el envío de material pornográfico a través del sistema de comunicación electrónica, denotando falta de capacidad e idoneidad para el desempeño del cargo e inobservancia del Reglamento Interno de Trabajo', es imprescindible precisar si dicha conducta se encuadra en el citado inciso a del artículo 25 del Decreto Supremo 003-97$\mathrm{TR}$, cuyo texto prevé que 'falta grave es la infracción por el trabajador de los deberes esenciales que emanan del contrato de tal índole, que hagan irrazonable la subsistencia de la relación'; agregando que dentro de las diversas variantes que la configuran se encuentra 'el incumplimiento de las obligaciones de trabajo que supone el quebrantamiento de la buena fe laboral, la reiterada resistencia a las órdenes relacionadas con las labores, la reiterada paralización intempestiva de labores y la inobservancia del Reglamento Interno de Trabajo o del Reglamento de Seguridad e Higiene, aprobados o expedidos, según corresponda por la autoridad competente, que revistan gravedad'.

6) De una simple constatación entre lo que establece el citado dispositivo legal y la conducta atribuida al recurrente, no se observa, prima facie, coherencia o relación alguna, salvo que se entienda que la misma supone, exclusivamente, una infracción al Reglamento Interno de Trabajo, que, según aparece del texto reseñado, podría permitir una interpretación mucho más extensiva de los tipos de conducta grave. Sin embargo, revisado el texto de dicho reglamento, obrante de fojas 119 a 152 de autos, se aprecia que, por el contrario, los 


\section{Daniel Ulloa Millares}

hechos imputados no son calificados como faltas graves que generan despido, conforme lo establece el artículo 113 de dicha norma, sino, y en el más perjudicial de los casos, como simples infracciones que solo generan sanción disciplinaria, según lo señalado en su respectivo artículo 110.

7) En efecto, aun asumiendo que los hechos atribuidos fuesen ciertos, los mismos podrían verse identificados en los incisos e ['Cometer dentro de las horas de trabajo o fuera de ellas actos contrarios a la disciplina, higiene o reñidos con la moral'], j ['Distraer a sus compañeros en horas de trabajo, así como leer periódicos, revistas, libros, etcétera sin ser parte de sus funciones'], s ['Usar temerariamente los bienes o instalaciones de la empresa'] y el inciso y ['Utilizar o usufructuar para actividades ajenas a SERPOST S.A. los teléfonos, télex, máquinas, equipos u otros bienes, o permitir su uso a terceras personas'] del referido artículo 110, mas, de ningún modo, como las consabidas faltas graves generadoras de despido. Este solo hecho, independientemente del tipo de sanción adoptada, implica, pues, una transgresión del principio de tipicidad sancionatoria que, como este Colegiado ya lo ha señalado en anteriores oportunidades, rige en el ámbito de los procedimientos disciplinarios de toda índole.

8) Un segundo aspecto que en cierta forma es consecuencia del anterior (solo en tanto se asuma la veracidad de los cargos imputados) tiene que ver con la intensidad de la sanción que, a estos efectos, tampoco resulta la adecuada. Si, conforme lo establece el artículo 108 del Reglamento Interno de Trabajo, son cuatro los tipos de medidas disciplinarias: amonestación verbal, amonestación escrita, suspensión temporal sin goce de remuneraciones y despido, y las mismas deben ser aplicadas tomando en cuenta los hechos, la gravedad de las faltas y los antecedentes del trabajador, resulta absolutamente desproporcionado e irrazonable, por decir lo menos, que, por los hechos denunciados, se proceda de inmediato y sin elemento de ponderación, a aplicar al recurrente la más grave de las medidas sancionatorias. Tal circunstancia, a juicio de este Colegiado, tergiversa los alcances del debido proceso, no solo en términos formales, sino fundamentalmente sustantivos" (la cursiva es nuestra).

En pocas palabras, establecer escalas de sanciones con falta de antecedentes impide realizar un despido si estas no se han cumplido en el caso concreto.

El mismo razonamiento lo podemos encontrar en otro proceso, el caso conocido como del trabajador ebrio(10), sentencia de fecha $10 \mathrm{de}$ octubre de 2008 emitida en el expediente No. 3169-2006:

"14. No obstante lo señalado en el fundamento anterior, este Tribunal considera que el despido del demandante viola el derecho constitucional al debido proceso sustantivo debido a que la Municipalidad emplazada al momento de imponerle la sanción lo hizo en contravención de los principios de razonabilidad y proporcionalidad, toda vez que no tuvo en cuenta lo establecido en el artículo 83 de su propio Reglamento Interno de Trabajo, el que señala que las sanciones disciplinarias de amonestación verbal o escrita, suspensión en sus labores o despido, se aplicarán en función de la gravedad de la falta cometida, la categoría, la antigüedad y los antecedentes disciplinarios del trabajador.

15. Por ello, este Tribunal considera que la sanción impuesta al demandante resulta desproporcionada e irrazonable, pues si bien conforme se ha señalado en fundamento que precede al demandante se le puede reputar que ha incurrido en la falta grave que se le imputa, no es menos cierto que en ningún momento ha incurrido

(10) Véase por ejemplo la noticia publicada el 14 de enero de 2009: http://diariocorreo.pe/ciudad/ir-ebrio-al-trabajo-no-seracausal-de-despido-148365/. 


\author{
El Reglamento Interno de Trabajo como fuente de Derecho: importancia y \\ visión jurisprudencial \\ The internal labor regulations as a source of Law: importance and \\ jurisprudential vision
}

\begin{abstract}
en algún acto de violencia, injuria o faltamiento de palabra verbal o escrita en agravio del empleador, del personal jerárquico o de otros trabajadores, ni ha ocasionado daño alguno al patrimonio ni al acervo documentario de la Municipalidad emplazada. Siendo así y teniéndose en cuenta que la Municipalidad, en la fundamentación de las cartas cuestionadas y durante el curso del proceso de amparo, no ha argumentado que el demandante tenga antecedentes disciplinarios, se debe concluir que la sanción impuesta (despido) no fue la más adecuada e idónea, pues la emplazada podía haberle impuesto cualquiera de las otras sanciones disciplinarias ya citadas anteriormente" (la cursiva es nuestra).
\end{abstract}

Si bien en este caso no se produjo el supuesto de la norma (concurrencia reiterada en estado de embriaguez o situación excepcional), el no poseer antecedentes disciplinarios y que el reglamento contemple varias sanciones hizo que el TC no acepte el despido.

Algo similar se puede apreciar en la sentencia del TC de fecha 12 de marzo de 2010 emitida en el Expediente No. 2267-2009 ${ }^{(11)}$ donde las sanciones incluidas en el reglamento interno de trabajo condicionaron la facultad disciplinaria del empleador. Y, por tanto, el despido fue declarado nulo.

En la sentencia del Expediente No. 1997-2011 de fecha 22 de octubre de 2012 el trabajador fue despedido:

"Por haber sido intervenido en inmediaciones del centro comercial Megaplaza, en horario de trabajo y haciendo uso de un bien de la institución (vehículo) que se encuentra bajo su custodia, usándolo de manera indebida en beneficio propio o de terceros. Asimismo, la Municipalidad emplazada afirma que el actor no contaba con la respectiva papeleta de salida tal como lo establece el Reglamento Interno de Trabajo, ni con la autorización de su jefe inmediato" (énfasis agregado).

Y el TC indicó lo siguiente:
"9. Asimismo, resulta pertinente indicar que el Reglamento Interno de Trabajo de la Municipalidad emplazada ${ }^{(12)}$ en su artículo 52 establece que: 'las faltas disciplinarias se tendrán en cuenta para la sanción respectiva, según sea el caso, la gravedad sobre el retraso, perjuicio o impedimento de la prestación o de los servicios públicos municipales, el daño causado o agravado sobre los bienes o instalaciones municipales, los males causados sobre sus compañeros de trabajo o pobladores de la comunidad, la exposición causada o riesgo sobre la salud o seguridad del centro de labores, el atraso o perjuicio originado sobre la productividad, seguridad, disciplina y armonía en las labores municipales; y, en consideración al comportamiento y antecedentes del trabajador'. Asimismo, el artículo 53 del Reglamento antes citado señala que: 'Para la aplicación de sanciones disciplinarias se observará los principios del proceso sancionador, a fin de garantizar (...) la razonabilidad en la aplicación de la sanción disciplinaria (...)'. Mientras que en su artículo 54 establece los tipos de sanciones disciplinarias, como son amonestación verbal, escrita, suspensión y despido, que resultarían aplicables por causa justa relacionada con la conducta del trabajador 'que afecte de modo directo la prestación de los servicios públicos municipales'. Que debió emplear la Municipalidad emplazada ante la supuesta omisión en la que incurrió el demandante al no contar con la papeleta de salida para trasladar a las señoras Juana Rosa Sepúlveda Samán y Rosa Maximina Rojas Flores para efectuar las

(11) La sentencia se puede revisar en: http://www.tc.gob.pe/jurisprudencia/2010/02267-2009-AA.pdf

(12) Véase en los siguientes enlaces: http://www.peru.gob.pe/docs/PLANES/10058/PLAN_10058_Reglamentos_Internos_de_ Trabajo_2011.pdf o http://www.municomas.gob.pe/SGW/gestionar/xtransparencia/reglament/arch0000000053.pdf 


\section{Daniel Ulloa Millares}

compras que habían sido autorizadas por el jefe inmediato, el señor Luis Alberto Orbezo Zamudio, conforme se deprende del fundamento 8 supra.

10. Por consiguiente, este Tribunal considera que el despido del que fue objeto el recurrente vulnera el derecho constitucional al debido proceso sustantivo debido a que la Municipalidad emplazada al momento de imponer al trabajador la sanción de despido lo hizo en contravención de los principios de razonabilidad y proporcionalidad, toda vez que no tuvo en cuenta lo establecido en los referidos artículos 52, 53 y 54 del Reglamento Interno de Trabajo, que contemplan las sanciones disciplinarias de amonestación verbal o escrita, suspensión en sus labores o despido, las cuales se aplicarán en función de la gravedad de la falta cometida, en consideración al comportamiento y antecedentes del trabajador".

Es por ello que este Tribunal concluye que la sanción impuesta al demandante resulta desproporcionada e irrazonable, pues si bien se le puede reputar que ha incurrido en la falta que le imputó la Municipalidad emplazada, en ningún momento ha incurrido en la afectación de la prestación de los servicios municipales ni ha ocasionado daño alguno al patrimonio ni al acervo documentario de la Municipalidad emplazada. Siendo así y teniéndose en cuenta que la emplazada, en la fundamentación de las cartas cuestionadas y durante el curso del proceso de amparo, no ha argumentado que el demandante tenga antecedentes disciplinarios, se debe concluir que la sanción impuesta (despido) no fue la más adecuada e idónea, pues la Municipalidad emplazada podía haberle impuesto cualquiera de las otras sanciones disciplinarias anteriormente citadas y previstas en su Reglamento Interno de Trabajo, por lo que corresponde estimar la demanda" (énfasis agregado).

La alegada vulneración al debido proceso y a los principios de racionabilidad y proporcionalidad también se puede ver en la sentencia de fecha 10 de agosto de 2009 emitida en el Expediente No. 5104-2008:

"12. Al respecto, cabe tener en cuenta lo establecido por el artículo 39 inciso b del Reglamento Interno de Trabajo Southern Perú 1998 que señala:

Artículo 39.- Son consideradas faltas leves las siguientes: (...) b) Salir del trabajo antes de la hora o ausentarse de él sin el permiso correspondiente.

13. Siendo así las cosas, este Tribunal considera que el despido del trabajador también viola el derecho constitucional al debido proceso sustantivo debido a que la empresa emplazada al momento de imponer a los 2 trabajadores la sanción de despido laboral, lo hizo en contravención de los principios de razonabilidad y proporcionalidad, por cuanto no tuvo en cuenta lo establecido en el artículo 36 inciso c de su propio Reglamento Interno de Trabajo, el cual señala que al aplicar una medida disciplinaria el Jefe o Supervisor tomará en cuenta los siguientes derechos del trabajador: c) Deberá ser proporcional a la gravedad de la falta cometida y a las circunstancias en que se produjo, debiendo servir como medida correctiva, a fin de evitar que se incurra nuevamente en ella (...); toda vez que los trabajadores habrían incurrido en una falta leve y en aplicación concordada de lo establecido por los artículos 40, 41, 42 y 43 del referido reglamento eran pasibles de que se les imponga las sanciones de amonestación escrita o en caso extremo la medida disciplinaria de suspensión, la cual de modo general no podía exceder de 3 días, pudiéndose excepcionalmente aplicar por más de 3 días, con la aprobación del Gerente o Jefe de División de la empresa.

14. Por ello, este Tribunal considera que la sanción impuesta por la demandada resulta desproporcionada e irrazonable, pues si bien conforme se ha señalado en el fundamento que precede, a los demandantes se les puede reputar que hayan incurrido en falta disciplinaria, no es menos cierto que teniéndose en cuenta que la empresa, en la fundamentación de las cartas cuestionadas y durante el 


\author{
El Reglamento Interno de Trabajo como fuente de Derecho: importancia y \\ visión jurisprudencial \\ The internal labor regulations as a source of Law: importance and \\ jurisprudential vision
}

\begin{abstract}
curso del proceso de amparo, no ha argumentado que los demandantes tengan antecedentes disciplinarios que haya merecido que se les imponga alguna sanción disciplinaria, se debe concluir que la sanción del despido, no fue la más adecuada e idónea, pues teniendo en cuenta la falta incurrida por parte de los trabajadores, la emplazada podía haberles impuesto cualquiera de las otras sanciones disciplinarias ya citadas anteriormente" (énfasis agregado).
\end{abstract}

No cabe duda que los empleadores -en su mayoría- buscan utilizar el incumplimiento del reglamento interno para sustentar el despido, pero ello no siempre ocurre como hemos podido ver. Así sucede en la Sentencia No. 1059-2009 de fecha 30 de noviembre de 2011 donde la existencia en el reglamento interno de una prohibición de traer bienes que no califiquen como enseres personales a un asistente de cabina no ayudó a justificar el despido, el cual fue declarado infundado.

Tampoco ello se logró en el caso resuelto en el Expediente No. 1177-2008, pues la sentencia de fecha 2 de junio de 2010 no avaló que los certificados médicos con los que el demandante justificaba su inasistencia al trabajo debían cumplir con la formalidad requerida por el reglamento interno (certificación del centro asistencial de Essalud). Y por ello declaró fraudulento el despido basado en ese incumplimiento. En efecto:

"15. Si bien el artículo 29 del Reglamento Interno de Trabajo de OSITRAN exige que a partir del vigésimo primer día de incapacidad temporal para el trabajo requiere certificación del centro asistencial de Essalud, ello no obsta que pueda entenderse justificada la inasistencia de un trabajador con un Certificado de Incapacidad Temporal para el Trabajo suscrito por un médico particular, más aún cuando el inciso h del artículo 25 del Texto Único Ordenado del Decreto Legislativo 728 no exige tal formalidad".

En otro caso, el TC anuló un despido porque no siguió el procedimiento establecido por el empleador. Así en la sentencia de fecha 17 de junio de 2004 emitida en el Expediente No. 34-2004-AA encontramos lo siguiente:

"2. El artículo 120 del Reglamento Interno de Trabajo de EPSEL S.A. prescribe el procedimiento que debe seguirse para imponer las medidas disciplinarias de suspensión por más de tres (3) días, estipulando que compete a la Sub Gerencia de Recursos Humanos la realización de la investigación pertinente, 'otorgando el plazo de 24 horas al trabajador para que efectúe el descargo respectivo, debiendo coordinar con la Gerencia General en el caso que la suspensión a aplicarse fuera mayor de diez (10) días'; asimismo, dicha norma legal dispone que las medidas de suspensión se aplicarán y darán a conocer por escrito al trabajador, 'observando siempre el principio de inmediatez'.

3. En el caso del demandante, no se ha seguido el mencionado procedimiento disciplinario, puesto que el Directorio le impuso directamente la sanción, sin la intervención de la Sub Gerencia de Recursos Humanos ni de la Gerencia General, como correspondía; tampoco se le concedió el mencionado plazo para que haga su descargo, ni se observó el principio de inmediatez, dado que se le hizo conocer la sanción el 7 de febrero de 2003, esto es, a casi dos meses de adoptado el acuerdo cuestionado, como se aprecia del Memorandum No. 066-2003-EPSEL S.A./GG que corre a fojas 261. En consecuencia, se vulneraron sus derechos al debido proceso y de defensa" (énfasis agregado).

Siguiendo esta línea de interpretación, la Sala de Derecho Constitucional y Social Permanente de la Corte Suprema de Justicia de la República calificó como acto de hostilidad en la casación laboral No. 8866-2013 de fecha 4 de octubre de 2013 un cambio de ciudad de trabajo que no respetó el procedimiento establecido por el empleador en su reglamento interno de trabajo.

En otros casos, cuando el reglamento interno ha incluido como causas de despido una simple mención a "las establecidas en el 


\section{Daniel Ulloa Millares}

Decreto Supremo 3-97-TR", el TC ha entendido que, en caso se acredite la falta grave, ello justifica el cese por el literal a del artículo 25. Esto se puede revisar en las sentencias emitidas en los expedientes No. 47-2012 (de fecha 3 de mayo de 2012), No. 4149-2012 (22 de mayo de 2013) o, No. 678-2014 (de fecha 3 de noviembre de 2015).

Y en un caso específico (sentencia de fecha 3 de noviembre de 2015 emitida en el Expediente No. 678-2014), el TC estableció cómo debería preverse la sanción:

"En la misma línea, el artículo 28, inciso b del Reglamento Interno de Trabajo de la Sociedad emplazada establece:

Art 28.- Son obligaciones de los trabajadores, entre otras: (...)

b) Acatar y cumplir las órdenes e instrucciones que por razones de trabajo sean impartidas por sus supervisores, siendo responsables de la labor que se les encomiende (...)".

Ante ese contexto, y dado que el trabajador admitió que los hechos imputados como falta grave ocurrieron y que además tenía antecedentes disciplinarios (una llamada de atención y una suspensión), entonces el TC consideró que el despido resultó proporcional a la gravedad de los hechos acontecidos y no vulneró el principio de tipicidad porque la falta está establecida "en el artículo 25, inciso a del Decreto Supremo 003-97-TR y en el artículo 28, inciso b del Reglamento Interno de Trabajo". La demanda, por tanto, fue declarada infundada.

El contenido del Reglamento Interno de Trabajo también fue considerado para sustentar el despido en el conocido caso Baylón Flores (sentencia de fecha 28 de noviembre de 2005 emitida en el Expediente No. 206-2005). O, inclusive, para limitar de manera discutible el derecho al trabajo de un postulante por el solo hecho de tener familiares en la entidad pública a la que se presentó (sentencia de fecha 8 de noviembre de 2007 emitida en el expediente No. 2734-2007), prohibición prevista en el reglamento interno de dicha entidad.

Otras veces, el Reglamento Interno ayuda a consolidar la comisión de una falta. En la sentencia de fecha 19 de marzo de 2003, emitida en el expediente No. 97-2003:
"3. Con respecto al derecho al trabajo, el Decreto Supremo 003-97-TR, Ley de Productividad y Competitividad, señala como causa de extinción del contrato de trabajo el despido en la forma y casos previstos por ley, precisando como causa justa de despido la falta grave, que la define como la transgresión a los deberes esenciales que emanan del contrato; lo que se complementa con el Reglamento Interno de Trabajo de la Southern Perú Limited, cuyo artículo 48 prescribe 'la comisión de falta grave constituye causa justa de despido del trabajador. Esta supone infracción a los deberes esenciales del Contrato de Trabajo, lo cual hace irrazonable la subsistencia del vínculo laboral [...]', tipificando como falta grave en el inciso a 'el incumplimiento de las obligaciones de trabajo [...]'.

4. A mayor abundamiento, el artículo 9 del Reglamento Interno de Seguridad de la Empresa dispone '[...] que todo trabajador, antes de iniciar cualquier trabajo, debe cerciorarse de que su labor no implique un riesgo o posibilidad de accidente para sí o para otras personas'; precisando el artículo 11: '[...] es responsabilidad del trabajador evitar en todo momento cualquier posibilidad de accidente[...]'; en tanto que el artículo 13 dice: '[...] los trabajadores cumplirán con los métodos y/o procedimientos establecidos tendientes a reducir al mínimo los riesgos de accidentes inherentes a su ocupación [...]'. En el caso de autos, la negligencia y temeridad demostradas por el demandante al conducir la locomotora de vagones, sin tener licencia para ello, y empujar en un mismo movimiento los 22 vagones, a sabiendas de que el volteador de carros se encontraba en mal estado -conforme lo refiere durante su manifestación que obra a fojas 69 de autos-, constituye falta 


\section{El Reglamento Interno de Trabajo como fuente de Derecho: importancia y visión jurisprudencial \\ The internal labor regulations as a source of Law: importance and jurisprudential vision}

grave en aplicación de los dispositivos citados" (énfasis agregado).

Lo mismo ocurre en la sentencia de fecha 10 de diciembre de 2009, Expediente No. 2887-2008:

"Asimismo, entre las causas justas de despido relacionadas con la conducta del trabajador, deben tenerse en cuenta la no observancia del Reglamento Interno de Trabajo y el proporcionar información falsa al empleador con la intención de causarle perjuicio u obtener una ventaja, conforme a lo previsto por los incisos a y d del artículo 25 del Decreto Supremo 003-97-TR.

7. De la carta de imputación de cargos y de despido se aprecia que la falta grave atribuida al recurrente se sustenta en el hecho de que suscribió con el INEN otro contrato de trabajo, contraviniendo con tal hecho lo dispuesto por el inciso ñ del artículo 20 del Reglamento Interno de Trabajo para los trabajadores comprendidos en el régimen laboral de la actividad privada de EsSalud, aprobado por la Resolución de Presidencia Ejecutiva No. 139-PEESSALUD-99 de fecha 21 de junio de 1999, que establece que está expresamente prohibido a los trabajadores percibir doble remuneración o pensión, salvo aquellos casos permitidos por la ley, situación que no ocurre en el caso materia de autos" (énfasis agregado).

La Sala de Derecho Constitucional y Social Permanente de la Corte Suprema de Justicia de la República fue más enfática. En la Casación Laboral No. 4512-2009 de fecha 15 de setiembre de 2010 señaló que:

"Para los efectos del caso de autos constituye falta grave la inobservancia del Reglamento Interno de Trabajo, aprobado o expedido, según corresponda, por la autoridad competente que revista gravedad (...) bastará el incumplimiento de cualquiera de las disposiciones contenidas en el Reglamento Interno de Trabajo que revista de gravedad para que se configure una falta grave, ya que el inciso a del artículo 25 del Decreto Supremo 003-97-TR, no hace distinción respecto de los capítulos que contiene la norma interna, sancionando por igual la inobservancia de cualquiera de sus disposiciones en la medida que el incumplimiento revista gravedad".
El Reglamento Interno de Trabajo sirve, además, para definir cuáles son los cargos que el empleador califica como de confianza o de dirección. Al respecto, se puede revisar la sentencia del TC de fecha 23 de enero de 2015 emitida en el Expediente No. 2842013, así como la sentencia de fecha 19 de abril de 2016 emitida en el Expediente No. 760-2013.

Otra importante función que cumple el Reglamento Interno de Trabajo es la de otorgar un indicio de laboralidad para una relación civil. Sobre esto se puede revisar la sentencia del TC de fecha 17 de marzo de 2009 emitida en el Expediente No. 38652008 o la sentencia del Expediente No. 14172012 de fecha 6 de abril de 2016. Parece evidente que, si a un locador le exigen cumplir las normas del Reglamento Interno de su contratante, entonces podemos concluir que dicho prestador no tiene autonomía $y$, en consecuencia, es un trabajador.

En suma, la importancia del Reglamento Interno radica en la posibilidad de regular aspectos que no están contemplados en las normas y su elaboración debería ser específica, según cada empleador, no siendo recomendable copiar modelos existentes pues con ello se pierde la posibilidad de establecer reglas. Asimismo, y dada la práctica jurisprudencial, el tema disciplinario debería regularse de manera muy precisa pues ello siempre va a ser utilizado como referente en cada evaluación de sanción.

Lamentablemente, la abundancia de normas heterónomas en el ordenamiento peruano le ha restado importancia al reglamento interno de trabajo, pero los cambios en las formas de producción permiten que el empleador pueda responder de manera más rápida a la regulación de las mismas mediante esta fuente. 


\section{Daniel Ulloa Millares}

Finalmente, somos de la opinión que el Decreto Supremo 39-91-TR debería ser actualizado en su contenido dado que su texto ya no coincide con la situación normativa vigente. $\mathrm{O}$, si somos más avezados, podríamos pensar en eliminarlo, pues su existencia no hace más que redundar el contenido del poder de dirección del empleador (esto es, un empleador no necesita la norma para poder formalizar sus reglas de juego). Creemos que carecer de base normativa no perjudicaría su noción de fuente de derecho dado que, de igual manera, si cumple con ser general y abstracta, podrá ser aplicable a todos los trabajadores dentro de su ámbito.

\section{Referencias Bibliográficas}

Boza, Guillermo. 2011. Lecciones de derecho del trabajo. Lima: Fondo Editorial de la Pontificia Universidad Católica del Perú.

Neves, Javier. 2009. Introducción al derecho del trabajo. Lima: Fondo Editorial de la Pontificia Universidad Católica del Perú. 